\title{
PERSPECTIVES
}

\section{Teaching Medicine to Non-English Speaking Background Learners in a Foreign Country}

\author{
Gurpreet Dhaliwal, $M D^{1,2}$ \\ ${ }^{1}$ San Francisco VA Medical Center, San Francisco, CA, USA; ${ }^{2}$ University of California San Francisco, San Francisco, CA, USA.
}

Teaching abroad exposes medical educators to unfamiliar teaching methods and learning styles that can enhance their overall teaching repertoire. Based on the author's experience teaching residents for one month at a community hospital in Japan and a review of the non-English speaking background (NESB) educational literature, pedagogical principles and lessons for successful international NESB instruction are outlined. These methods include understanding the dissimilar linguistic, cultural, and academic backgrounds of the learners, emphasizing pace and clarity of speech, presenting a conceptual framework instead of detailed discourse on subjects, and regular visual reinforcement of spoken words. The limitations introduced by the language barrier and the use of interpreters are briefly discussed. As society and institutions of higher learning become more global and multicultural, clinician-educators may benefit from teaching in other countries in order to enhance their teaching skills with NESB learners, both abroad and in their own institutions.

KEY WORDS: Non-English speaking background; English as a second language; Medical education; International teaching.

$\mathrm{J}$ Gen Intern Med 24(6):771-3

DOI: $10.1007 / \mathrm{s} 11606-009-0967-\mathrm{z}$

(c) Society of General Internal Medicine 2009

\section{INTRODUCTION}

International teaching provides clinician-educators an opportunity for professional development and cultural immersion. ${ }^{1,2}$ The experience also exposes medical educators to new teaching methods and learning styles that can enhance their overall teaching repertoire. Language and communication issues are understandably principal concerns when contemplating a foreign teaching assignment.

The opportunity to teach medical residents in another country gave me a better understanding of the challenges that non-English speaking background learners face during English instruction. This experience prompted me to reflect upon which teaching strategies were most effective and to study the non-English speaking background (NESB) and English as a second language (ESL) literature. Although my observations come from a single center in Japan, my research and advice is meant to serve as a guide for clinician-educators

Received November 6, 2008

Revised February 4, 2009

Accepted March 17, 2009

Published online April 18, 2009 who are contemplating international teaching assignments worldwide.

\section{TEACHING CONTEXT}

I was invited to teach for one month at a 419-bed community hospital in Chigasaki, Japan where 23 residents train in a 2-year program analogous to a transitional internship year in the United States. I provided instruction in English in lectures and case conferences and on rounds in the medical inpatient ward, intensive care unit, and emergency department.

In Japan, students study English for six to eight years before residency, with greater emphasis on written rather than conversational English. ${ }^{3-7}$ Most Japanese medical students and residents use Japanese textbooks; a minority read English texts and articles regularly. There is increasing use of English Internet resources including PubMed and UpToDate, and English journal articles are commonly discussed. I observed a spectrum of spoken English proficiency among the residents, and there were usually one or more highly capable physician interpreters in any group setting.

The added cognitive load of a second language while learning medicine should not be underestimated. I have great admiration for the residents who deciphered the medical lexicon of a foreign language while simultaneously processing the facts and reasoning strategies of their new profession. An analogy would be American residents, many of whom have studied a foreign language such as Spanish for years, trying to learn from an exclusively Spanish-speaking professor during their first months of internship.

\section{TEACHING PRINCIPLES}

Adapt to the local educational culture. A divergent method of instruction may be counterproductive or suboptimal in a culture that learns and processes information differently. ${ }^{8} \mathrm{My}$ initial resources for advice about local pedagogy were faculty at my university who had taught in Japan and conversations with visiting Japanese physicians. In Japan I made educational styles an early topic of conversation and closely observed the teaching style of the local faculty.

The Japanese educational system emphasizes didactic lectures and diligent study of written material with less instruction using interactive questioning and analytical reasoning. ${ }^{4,9,10} \mathrm{I}$, therefore, provided a lecture-based curriculum but also used interactive techniques (particularly directed questioning) during didactic sessions and bedside rounds. I regularly 
recalibrated this hybrid approach with feedback from the faculty and the chief resident. Questions from the residents, typically after class, were the clearest indicator of learner engagement.

Speak clearly and slowly. Listening is a demanding task that limits complete understanding for some NESB students. ${ }^{11,12}$ Unlike reading, where the learner can control the pace of information and reflect, listening requires several additional cognitive steps for comprehension ${ }^{13}$ including distinguishing similar sounding words, analyzing stress and intonation, and deciphering colloquialisms. One study of Japanese students demonstrated increased comprehension with a slower English speaking pace, ${ }^{14}$ which facilitates native-language reprocessing and note taking ${ }^{11,15}$. A colleague with extensive international teaching experience gave me the following advice: If you are not aware that you are speaking slowly, then it is not slow enough.

It is advisable to choose the most straightforward words. Even when "listless" best describes the patient, phrases such as "very tired" will minimize uncertainty. It is imperative to avoid idiomatic, jargon, or slang English. ${ }^{7,11,15}$ Phrases like "the bottom line" or "start from scratch" lack meaning for many NESB learners and can be distracting. Emphasis on enunciation-which brings both clarity and a decrease in speech rate-is advisable. Contractions like "can't" or "haven't" are easily confused with "can" and "have."

Less is more. A common teaching mistake is presenting too much information. ${ }^{16,17}$ When I taught hypercalcemia, by necessity of unhurried and deliberate speech, I focused on the two leading causes-hyperparathyroidism and malignancy-with only a brief mention of granulomatous disease and exogenous calcium/vitamin D. I never mentioned the less common entities such as the minor effect of hydrochlorothiazide or the rare consequence of immobility. (Notably, I overlooked a more prevalent cause in certain parts of my host country: HTLV-1 infection.) Spending time on more common diagnoses allows time to clarify, repeat, and assess understanding in a way that encyclopedic coverage of a topic does not.

By limiting information to the essential concepts a teacher can provide a basic cognitive structure and outline (scaffolding) and allow students to develop and organize detailed knowledge through their own reading and experiences ${ }^{18,19}$. Others have found that providing opportunities for before-and aftersession reading has improved understanding of basic vocabulary and has been well received by NESB students. ${ }^{7,11}$ Had I been more cognizant of this, I would have made a habit of providing my next lecture's topic in advance and would have advised a reading topic after bedside sessions and case discussions.

Use the board. Another helpful suggestion found in the literature is the use of visual reinforcement of the material covered in lectures. ${ }^{7,11,15,20}$ While writing or drawing on the board may be perceived as "dead time" ${ }^{21}$, the change of pace can ease the burden of uninterrupted listening ${ }^{11}$ and provide time for note taking, translation, or questioning. Writing on the board also helps students grasp key important concepts and vocabulary. In distinction to prepared computer slides, sketches on a board allowed for modifications as the situation demanded (e.g., simplifying, reconstructing, allowing for the addition of a Japanese phrase).

The board was a critical tool in providing instruction on cases that were presented in the classroom. Writing on the board facilitated confirmation of the spoken words of the presenter and created a visual display of the case for the residents to follow (capitalizing on the strength of their reading comprehension). The tenants of clinical reasoning were emphasized by choosing which clinical facts were important enough to write on the board and then linking differential diagnoses to the recorded clinical details. Concept maps ${ }^{22,23}$ readily lent themselves to improvised diagrams and proved useful on several occasions.

Understand the silence. Directed questioning of the teacher is uncommon in many countries, where the absence of questions reflects respect and local learning style rather than indifference. For instance, Malaysian students in one study viewed "problem" students as those who challenged their teachers. ${ }^{24}$ Furthermore, some NESB learners are hesitant to vocalize thoughts or questions because of concerns about their English language proficiency; ${ }^{12,15}$ I oftentimes encountered residents who apologized for their very admirable conversational skills.

Second language communication adds to the complexity and anxiety of answering a question, but it is important to remain committed to this teaching format to foster familiarity and confidence in this type of interaction between learner and teacher. I typically asked one person (rather than the group); used a simple sentence structure but kept the content cognitively rigorous ("what are the important physical exam findings in pericarditis?") $)^{8,25}$; and clarified my question by repeating, rephrasing, or seeking translation when necessary. I praised all efforts to speak English yet scrutinized the medical content of their response at a more demanding level.

Challenges posed by the language barrier. Optimal communication and understanding require language fluency ${ }^{26}$ whereas a partial language barrier creates impediments to teaching that are not easily circumvented. It can be difficult to share anecdotes, mistakes, or humor, which sometimes make for the most enduring lessons. I was unable to model history taking at the bedside with patients. I regret not using resident names earlier for fear of mispronunciation and thereby forgoing stronger teacher-learner bonds. ${ }^{7,8}$ Finally, the language (and cultural) divide made receiving constructive feedback from the residents difficult.

When the message was nuanced or critical, I worked with a physician-interpreter. For example, when clinical features subtly supported or refuted a diagnosis, carefully chosen words were essential. Use of an interpreter slowed the pace of the session, but in return I saw polite attention transform into genuine understanding. Detailed considerations for collaborating with interpreters in international teaching venues have been discussed elsewhere. ${ }^{27,28}$

\section{CONCLUSION}

International teaching is a valuable professional development experience which enhances a medical teacher's pedagogical skills. It should not be overlooked that clinical skills, the underlying currency of the clinician-educator, will also grow in 
an environment with disproportionate exposure to interesting cases and ample time to learn new diseases, diagnostic approaches, and management strategies.

The trend toward an increasingly multicultural and global society will bring more NESB learners to English instruction classrooms and clinics and will send more English-speaking teachers and students into foreign medical education systems. Proficiency in these teaching approaches and an understanding of the different linguistic, cultural, and academic backgrounds of NESB learners will be increasingly important for clinician-educators.

Acknowledgements: The author thanks Christy Boscardin $\mathrm{PhD}$, Masami Matsumura MD, Tetsumasa Kamei MD, Alan Teo MD, and Lawrence Tierney MD for their review and comments on this manuscript.

Financial support: None.

\section{Conflict of Interest: None disclosed.}

Corresponding Author: Gurpreet Dhaliwal, MD; San Francisco VA Medical Center, 4150 Clement Street (111), San Francisco, CA 94121, USA (e-mail: gurpreet.dhaliwal@va.gov).

\section{REFERENCES}

1. Jarecky RK, Sandifer MG. Faculty members' evaluations of sabbaticals. J Med Educ. 1986;61:803-7.

2. Harris IB, Wempner J. Continuing medical education reconceived evaluation of a sabbatical program for physicians. Acad Med. 1996;71 (suppl 10):S46-8.

3. TOEFL® Test and Score Data Summary for TOEFL Internet-based and Paper-based Tests: 2007 Test Data. Available at: http://www.ets.org/ Media/Research/pdf/71943_web.pdf Accessed February 26, 2009.

4. Teo A. The current state of medical education in Japan: a system under reform. Med Educ. 2007;41:302-8.

5. Morse Z, Nakahara S. English language education in Japanese dental schools. Eur J Dent Educ. 2001;5:168-72.

6. Nuttall M. English in Japan. Jpn Railw Transp Rev. 2000;25:56.

7. Choi M. Korean students in Australian universities: Intercultural issues. High Educ Res Dev. 1997;16:263-82.
8. Jackson FR. Seven strategies to support a culturally responsive pedagogy. J Reading. 1993;37:298-303.

9. Tierney LM Jr. An experience in Japanese academic medicine. West $\mathrm{J}$ Med. 1994;160:139-45

10. Teo AR. Misperceptions of medical education in Japan: how reform is changing the landscape. Keio J Med. 2007;56:61-3.

11. Mulligan D, Kirkpatrick A. How much do they understand? Lectures, students and comprehension. High Educ Res Dev. 2000;19(3):311335.

12. Chur-Hansen A. Teaching support in the behavioural sciences for nonenglish speaking background medical undergraduates. Med Educ. 1999;33:404-10.

13. Flowerdew J. Research of relevance to second language lecture comprehension-an overview. In: Flowerdew J, ed. Academic Listening. Cambridge: Cambridge University Press; 1994:10.

14. Griffiths $\mathbf{R}$. Speech rate and NNS comprehension: A preliminary study in time-benefit analysis. Language Learning. 1990;40:311-36.

15. Lee DS. What teachers can do to relieve problems identified by international students. New directions for teaching and learning. 1997;70:93-100

16. Dempster FN. Exposing our students to less should help them learn more. Phi Delta Kappan. 1993;74(6):433-7.

17. Halpern DF, Hakel MK. Applying the science of the learning to the university and beyond. Changes. 2003;July/August:36-41.

18. Tony Greening. Scaffolding for Success in Problem-Based Learning. Available at: http://www.med-ed-online.org/f0000012.htm. Accessed February 26, 2009.

19. Harland T. Vygotsky's zone of proximal development and problem-based learning: linking a theoretical concept with practice through action research. Teach High Educ. 2003; 2: 263-272.

20. Giannini AJ, Giannini JN, Melemis SM. Visual symbolization as a learning tool: teaching pharmacology to international audiences. J Clin Pharmacol. 1997;37:559-65.

21. Orlander JD. Twelve tips for use of a white board in clinical teaching: reviving the chalk talk. Med Teach. 2007;29:89-92.

22. Torre DM, Daley B, Stark-Schweitzer T, Siddartha S, Petkova J, Ziebert M. A qualitative evaluation of medical student learning with concept maps. Med Teach. 2007;29:949-55.

23. Malu KF, Figlear MR. Six active learning-based teaching tips: promoting success for ESL nursing students. Nurse Educ. 2001;26:204-8.

24. Hunt DD, Khlaid BAK, Shahabudin SH, Jaafar R, Carline JD. A crosscultural comparison of problem students on clinical rotations. Teach Learn Med. 1995;7:8-12.

25. Choi LL. Literature review: issues surrounding education of English-asa-Second Language (ESL) nursing students. J Transcult Nurs. 2005; 16:263-8

26. Bruzzi JF. The words count-radiology and medical linguistics. N Engl J Med. 2006;354:665-7.

27. Brown DS, Donaldson N. Tips for teaching quality concepts to international audiences. J Healthc Qual. 2002;24:36-40.

28. Gerard DR. Teaching overseas. Emerg Med Serv. 2004;33:60-2, 66. 